Research Article

\title{
Probabilistic Analysis of Weathered Soil Slope in South Korea
}

\author{
Taeho Bong' and Younghwan Son $\mathbb{D}^{2}$ \\ ${ }^{1}$ Oregon State University, 101 Kearney Hall, Corvallis, OR 97331, USA \\ ${ }^{2}$ Department of Rural Systems Engineering and Research Institute for Agriculture and Life Sciences, Seoul National University, \\ Seoul, Republic of Korea \\ Correspondence should be addressed to Younghwan Son; syh86@snu.ac.kr
}

Received 4 April 2018; Revised 25 May 2018; Accepted 25 June 2018; Published 18 July 2018

Academic Editor: Tiago Ferreira

Copyright (c) 2018 Taeho Bong and Younghwan Son. This is an open access article distributed under the Creative Commons Attribution License, which permits unrestricted use, distribution, and reproduction in any medium, provided the original work is properly cited.

\begin{abstract}
Rainfall is a major trigger of shallow slope failures, and it is necessary to consider the spatial correlation of soil properties for probabilistic analysis of slope stability in heterogeneous soil. In this study, a case study of a weathered soil slope in Korea was performed to identify the rainfall-induced landslides considering the spatial variability of the soil properties and the probabilistic rainfall intensity depending on the return period and the rainfall duration. Various laboratory tests were performed to determine the physical properties of the site, and an electrical resistivity survey was carried out to understand the soil strata. Cohesion, friction angle, and permeability were considered as random variables considering the spatial variability, and the probabilistic rainfall intensities for return period of 2, 5, 10, 50, 100, and 200 years were used to consider the effects of rainfall infiltration. The results showed that a probabilistic framework can be used to efficiently consider the spatial variability of soil properties, and various slope failure patterns were identified according to the spatial variability of the soil properties and the probabilistic rainfall intensity.
\end{abstract}

\section{Introduction}

Shallow slope failure (typically $1-3 \mathrm{~m}$ deep) due to heavy rainfall during rainstorms and typhoons is common in mountain areas and take the form of translational slides, which form parallel to the original surface $[1,2]$. Over the past decade, many studies on rainfall pattern changes due to climate change have been carried out, and climate change has resulted in changes in rainfall patterns that can cause less frequent, but more intense rainfall events $[3,4]$.

One of the main triggering factors for landslides is heavy rainfall [5-8], and the abnormal climate and localized heavy rainfall caused by climate change may lead to more frequent landslides [4, 8-12]. For this reason, the prediction of rainfall-induced landslides is becoming more important, and the infinite slope model is usually implemented for the stability analysis of natural slopes; this model is appropriate when the horizontal dimensions of the surface are relatively much larger than the vertical depth of the potential failure slope. In addition, physically-based models have frequently been used in the framework of early warning systems devoted to rainfall-induced landslide hazard monitoring [13], and infinite slope model is commonly used to assess the factor of safety. However, the traditional infinite slope equation assumes homogeneous or averaged soil properties, and the potential failure surface is always fixed at the base of the slope [14] or wetting front depth (WFD). Although the uncertainties of the soil can be considered through the probabilistic analysis, the potential failure surface is still fixed and the probability of failure can be underestimated if the soil properties are treated as random variables without considering the spatial variability.

Geomorphological processes can lead to soil regions characterized by a degree of spatial heterogeneity [15], and the spatial variation can occur at various scales depending on the soil forming factors such as parent material, climate, topography, time, and so on. Describing and understanding the complexity of the interacting processes of soil formation has been a challenge, and geostatistics assumes that the variation of a property such as soil is continuous, which is 
generally more realistic for soil [16]. If the spatial variability of soil properties is considered in the probabilistic analysis, the soil strength can vary depending on the depth considering the spatial correlation structure, and the potential failure surface can occur at various depths. Considering these features, some recent studies focused on the probabilistic analysis of slope stability in heterogeneous soil considering the spatial variability.

For example, Cho [17] identified the effect of spatial variability of unit weight and shear strength parameters using a limit equilibrium method, also, Griffiths et al. [18] investigated the effect of the spatial variability of shear strength parameters using the random finite-element method (RFEM), and Griffiths et al. [14] performed infinite slope analysis considering spatial variability of soil and showed that the potential failure surface can occur at various depths depending on spatial variability. Jiang et al. [19] identified the effect of spatial variability of shear strength parameters using a nonintrusive stochastic finite element method. Cho [20] discussed the effect of spatial variability of permeability on infinite slope stability and the distribution of failure depth due to rainfall infiltration. However, the saturated permeability is often depth-dependent, and Dou et al. [21] investigated the effect of spatial variability of permeability considering nonstationary random field of the saturated permeability as an extension of Cho's [20]. In a similar vein, Li et al. [22] conducted reliability analysis of an infinite slope considering the linear trend of shear strength parameters in a random field. Li et al. [23] also proposed a multiple response-surface method for efficient slope reliability analysis considering spatial variability, and Cai et al. [24] conducted a cross-correlation analysis to determine the impact of heterogeneity of permeability, soil cohesion, and soil friction angle on slope stability.

In previous studies, the random variables most frequently considered when analyzing spatial variability of the soil properties are shear strength parameters (cohesion, $c$ and friction angle, $\phi$ ), and the permeability has also been considered in slope stability analysis due to rainfall infiltration. In practice, other important factors for estimating the probability of landslides occurrence are the intensity of rainfall and duration time [25], which are climatic factors. Rainfall is a major cause of landslides, and it is known that spatial and temporal variability is very high [26]. Therefore, it is important to consider and evaluate the appropriate probabilistic rainfall intensity for predicting the actual probability of landslide occurrence. However, little is known about the role of spatial variability of soil properties in probabilistic analysis of slope stability considering the probability rainfall intensity.

The purpose of this study was to identify the probability of failure of rainfall-induced landslides considering the spatial variability of soil properties and probabilistic rainfall intensity. A case study of shallow slope failure of weathered residual soil slope in Jangheung, Korea, was performed to verify the probabilistic analysis framework. The soil strata of the slope were identified, and the site investigation point was selected through electrical resistivity survey. Then, the soil physical properties and infiltration characteristics of unsaturated soil on natural slope were investigated, and two shear strength parameters $(c$ and $\phi)$ and permeability were considered as random fields. A slope stability analysis was performed using an infinite slope model, and the probabilistic rainfall intensity for 2, 5, 10, 50, 100, and 200 years frequency for the study area was considered. A series of Latin hypercube sampling- (LHS-) [27] based Monte Carlo simulations was conducted to investigate the effect of the spatial variability of soil properties on the mechanism of slope failure during periods of rain infiltration. Consequently, the probability of slope failure according to the probabilistic rainfall intensity and spatial variability of soil properties was estimated. How soil properties and climatic factors affect slope stability were then discussed.

\section{Random Field}

Nearly all natural soils are highly variable in their properties, and their variability shows a spatial correlation. The spatial variability of soil properties can be effectively considered using random field theory, and probabilistic analyses that incorporate the spatial variability of soil properties as random fields are more appropriate to consider the uncertainty of soil than those considering soil properties as a single random variable.

2.1. Spatial Variability of Soil. Because of complex geological and environmental processes, soil is inherently heterogeneous, and its properties can be highly variable and spatially correlated in the vertical and horizontal directions. The spatial correlation of soil properties is known to influence the geotechnical response of soil, and it brings unavoidable uncertainty in design, leading to unexpected soil responses $[15,28]$. These uncertain spatial properties can be characterized using random field theory [29, 30]. Vanmarcke [29] used a scale of fluctuation (SOF, $\delta$ ) to describe the extent of how soil properties are spatially correlated. Various methods are available to estimate the SOF, and the simplest approach is to fit the theoretical autocorrelation function (ACF, $\rho$ ) to the empirical ACF [31-34]. However, determining a theoretical ACF may not be easily implemented because a large amount of data is required. Therefore, some theoretical ACFs are usually used to characterize the spatial correlation of soil properties, and the single exponential ACF has been widely used to model the inherent spatial variability of soil properties in probabilistic analysis of slope stability [23]:

$$
\rho\left(x_{1}, x_{2}\right)=\exp \left(-\frac{\left|x_{1}-x_{2}\right|}{l}\right),
$$

where $l$ represents the autocorrelation distance and reflects the rate at which the correlation decays between two points $\left(x_{1}, x_{2}\right)$. The SOF implied by the single exponential autocorrelation function is equal to twice the value of the autocorrelation distance $(\delta=2 l)$.

2.2. Random Fields. In this study, the Karhunen-Loève expansion (KLE) was adopted to generate random fields because it is an efficient method for random field 
discretization with a desired level of accuracy and provides the greatest accuracy when an exponential ACF is used [35].

The KLE of a random field with a mean value $\left(\mu_{\omega}\right)$ and a variance $\left(\sigma_{\omega}^{2}\right)$ is given by Spanos and Ghanem [36]:

$$
\omega(x, \theta)=\mu_{\omega}(x)+\sum_{i=1}^{\infty} \sigma_{\omega} \sqrt{\lambda_{i}} f_{i}(x) \xi_{i}(\theta), \quad x \in \Omega,
$$

where $\lambda_{i}$ and $f_{i}(x)$ are the eigenvalues and eigenfunctions of the covariance function, respectively, and $\xi_{i}(\theta)$ represents the uncorrelated zero mean random variables. For practical implementation, the discretization of the random field $\omega(x, \theta)$ is obtained by truncating the series expansion at the $M$ th term:

$$
\omega(x, \theta)=\mu_{\omega}(x)+\sum_{i=1}^{M} \sigma_{\omega} \sqrt{\lambda_{i}} f_{i}(x) \xi_{i}(\theta) .
$$

The accuracy of the represented random field depends on the number of terms used in the KLE expansion, and the number of required terms is determined according to the ratio of the correlation length and the domain size [37].

Normal random fields are often used for modeling uncertainties with spatial variability for mathematical convenience and due to a lack of available data, but they are not applicable in many situations where the random variable is always non-negative. Therefore, the assumption of a lognormal distribution is appropriate as the soil properties used in this study are always non-negative $[38,39]$. In (3), if $\mu_{\omega}$ is zero and $\sigma_{\omega}$ is one, standard normal random fields are generated by KLE, and it can be transformed into lognormal random fields using (4) as follows:

$$
\widetilde{\omega}(x, \theta)=\exp \left(\mu_{\ln (x)}+\sigma_{\ln (x)} \sum_{i=1}^{M} \sqrt{\lambda_{i}} f_{i}(x) \xi_{i}(\theta)\right),
$$

where $\mu_{\ln (x)}$ and $\sigma_{\ln (x)}$ are equal to the mean and standard deviation of $\ln (x)$ of the underlying normal distribution.

\section{Rainfall-Induced Landslide}

In this section, the rainfall infiltration model and slope stability analysis model for unsaturated soils were described to assess the vulnerability of rainfall-induced landslides caused by rainfall, and then the probabilistic analysis procedure considering the spatial variability of soil properties was presented.

3.1. Rainfall Infiltration. In order to perform infiltration analysis considering spatial variability, the flow of water in multilayered soils should be considered, and this can be performed using differential equations that satisfy Darcy's law $[20,21,24,40]$. Alternatively, semianalytical and arealaveraged infiltration models have been established to study field-scale infiltration over soils with the variability of permeability based on the Green-Ampt [41] model [42, 43]. Chu and Marino [44] present a modified Green-Ampt model considering infiltration in multilayered soils. This model is able to deal with unsteady and steady rainfall events as well as ponding and nonponding conditions. Therefore, in this study, the infiltration model by Chu and Marino [44] was adopted to consider the spatial variability of permeability. Figure 1 shows infiltration of rainfall into an $n$-layered soil profile with permeability $(k)$ and initial volumetric water content $\left(\theta_{0}\right)$ for each layer.

When the wetting front is over layer $n$ at location $z\left(z_{n-1}<z \leq z_{n}\right)$, the infiltration rate $(i)$ under an initially ponded condition can be expressed as

$$
i_{z}=\frac{z+\Psi_{m n}}{\sum_{j=1}^{n-1}\left(\left(z_{j}-z_{j-1}\right) / k_{j}\right)+\left(\left(z-z_{n-1}\right) / k_{n}\right)},
$$

and cumulative infiltration $(I)$ is

$$
\begin{aligned}
I_{z} & =I_{z_{n-1}}+\left(z-z_{n-1}\right)\left(\theta_{\mathrm{s} n}-\theta_{0 n}\right) \\
& =\sum_{j=1}^{n-1}\left(z_{j}-z_{j-1}\right) \theta_{\mathrm{f} j}+\left(z-z_{n-1}\right) \theta_{\mathrm{f} n} .
\end{aligned}
$$

The travel time to depth $z$ can be expressed as

$$
\begin{aligned}
t_{z}= & t_{z_{n-1}}+\frac{\theta_{\mathrm{fn}}}{k_{n}}\left(z-z_{n-1}\right) \\
& +\theta_{\mathrm{f} n}\left[\sum_{j=1}^{n-1} z_{j}\left(\frac{1}{k_{j}}-\frac{1}{k_{j+1}}\right)-\frac{\Psi_{m n}}{k_{n}}\right] \ln \left(\frac{z+\Psi_{m n}}{z_{n-1}+\Psi_{m n}}\right),
\end{aligned}
$$

where $\theta_{s}$ is the saturated volumetric water content $\left(\mathrm{L}^{3} / \mathrm{L}^{3}\right)$, $\Psi_{m}$ is the pressure head (suction) (L), $\theta_{\mathrm{f}}$ is $\left(\theta_{\mathrm{s}}-\theta_{0}\right)$, and the subscript $n$ means the $n$-layer. In the case of nonponding, where the infiltration capacity of soil is greater than the rainfall intensity, all rainfall was assumed to infiltrate into the soil producing a piston flow. A detailed description of rainfall infiltration can be found in Chu and Marino [44].

3.2. Slope Stability of Unsaturated Soils. Rainfall-induced landslides usually have shallow surface failure depth, being the main cause of the reduction of negative pore water pressure in unsaturated soil due to rainfall infiltration $[5,45]$. Fredlund et al. [46] extended the shear strength criteria to unsaturated soils considering the matric suction, being possible to calculate the factor of safety along the potential failure surface (Figure 2) as

$$
F_{\mathrm{s}}=\frac{c^{\prime}+\sigma^{\prime} \tan \phi^{\prime}+\left(u_{\mathrm{a}}-u_{\mathrm{w}}\right) \tan \phi^{b}}{W \sin \beta \cos \beta},
$$

where $c^{\prime}$ is the effective cohesion, $\sigma^{\prime}$ is the effective normal stress, $\phi^{\prime}$ is the effective friction angle, $u_{\mathrm{a}}$ is the pore air pressure, $u_{\mathrm{w}}$ is the pore water pressure, $W$ is the weight of the soil slice per unit base area, $\beta$ is the slope angle, and $\phi^{b}$ is the angle indicating the rate of increase of shear strength relative to increased matric suction.

The shear strength contribution due to matric suction of unsaturated soil can be expressed as described by Fredlund and Rahardjo [45]:

$$
\tan \phi^{b}=\tan \phi^{\prime}\left(\frac{\theta-\theta_{\mathrm{r}}}{\theta_{\mathrm{s}}-\theta_{\mathrm{r}}}\right)=\tan \phi^{\prime} \cdot \Theta,
$$

where $\theta$ is the volumetric water content at potential failure surface and $\theta_{\mathrm{s}}$ and $\theta_{\mathrm{r}}$ are the saturated and residual volumetric water content, respectively. $\Theta$ is normalized volumetric water 


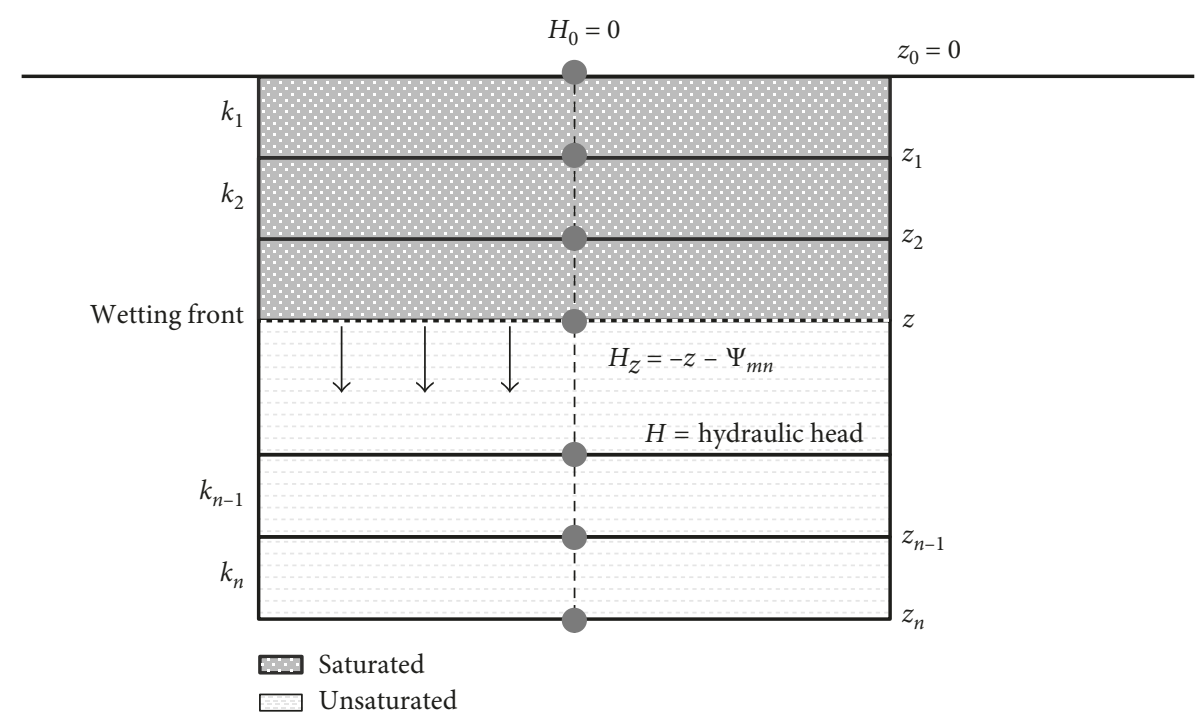

FiguRE 1: Infiltration into a layered soil profile under an initially ponded condition.

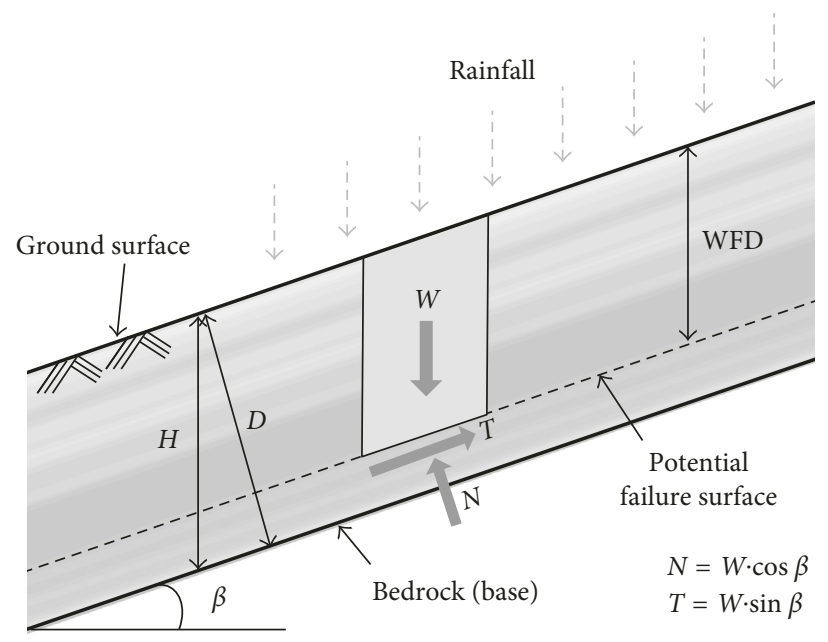

Figure 2: Infinite slope analysis model.

content, and the relationship between $\Theta$ and the matric suction $(\Psi)$ was given by van Genuchten [47]:

$$
\Theta=\frac{\theta-\theta_{\mathrm{r}}}{\theta_{\mathrm{s}}-\theta_{\mathrm{r}}}=\left[\frac{1}{1+(\alpha \Psi)^{n}}\right]^{m},
$$

where $\alpha, n$, and $m$ are van Genuchten's soil-water characteristic curve (SWCC) parameters. Considering (9) and (10), (8) can be expressed as

$$
F_{\mathrm{s}}=\frac{c^{\prime}+\sigma^{\prime} \tan \phi^{\prime}+\left(u_{\mathrm{a}}-u_{\mathrm{w}}\right) \tan \phi^{\prime}\left[1 /\left(1+(\alpha \Psi)^{n}\right)\right]^{m}}{W \sin \beta \cos \beta} .
$$

3.3. Probabilistic Analysis. The schematic view of the probabilistic slope analysis considering the spatial variability of soil properties and probabilistic rainfall intensity is shown in Figure 3. In order to consider the spatial variability of soil, random fields are generated for three soil properties $(c, \phi$, and $k_{\mathrm{s}}$ ), which are mainly considered as random variables in the

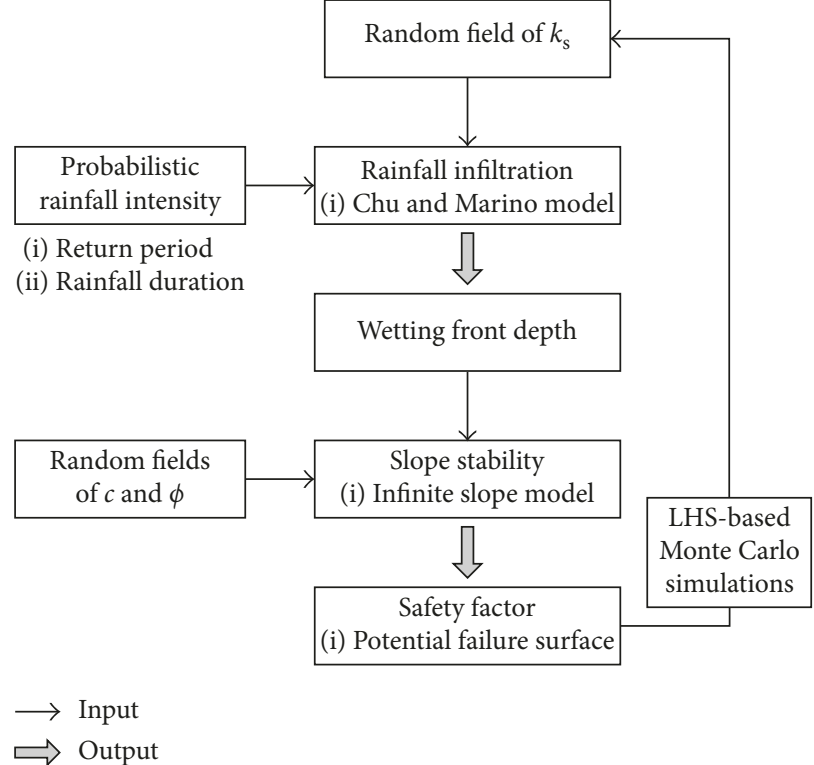

Figure 3: Flow chart for the probabilistic slope analysis.

existing studies on slope stability, and these are used as input values in the rainfall infiltration and slope stability analysis. The probability rainfall intensity depending on the return period and the rainfall duration is applied to consider rainfall characteristics for the site, and the WFD due to rainfall infiltration is estimated by Chu and Marino [44] model. Subsequently, the WFD is used for infinite slope stability analysis. As a result, the factor of safety for each depth and potential failure surface is estimated. This process is repeated to derive probabilistic results, and a series of LHS-based Monte Carlo simulations is conducted for efficient random sampling.

\section{Study Area}

4.1. Soil Physical Properties. The study area is located in Jangheung, Gyeonggi-do, South Korea $\left(37^{\circ} 45^{\prime} 03^{\prime \prime} \mathrm{N}\right.$, 


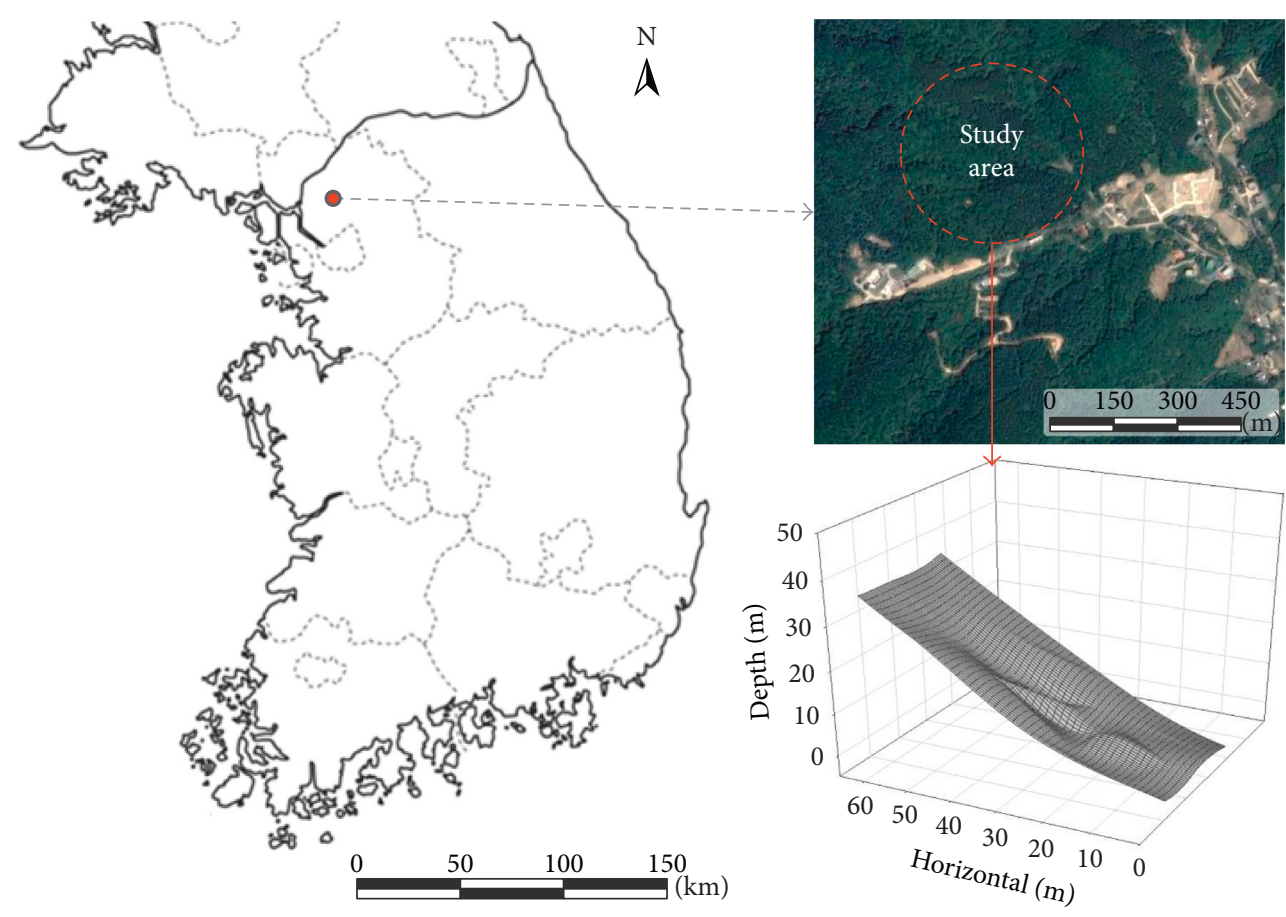

FIgURE 4: Location of the study area and surface plot.

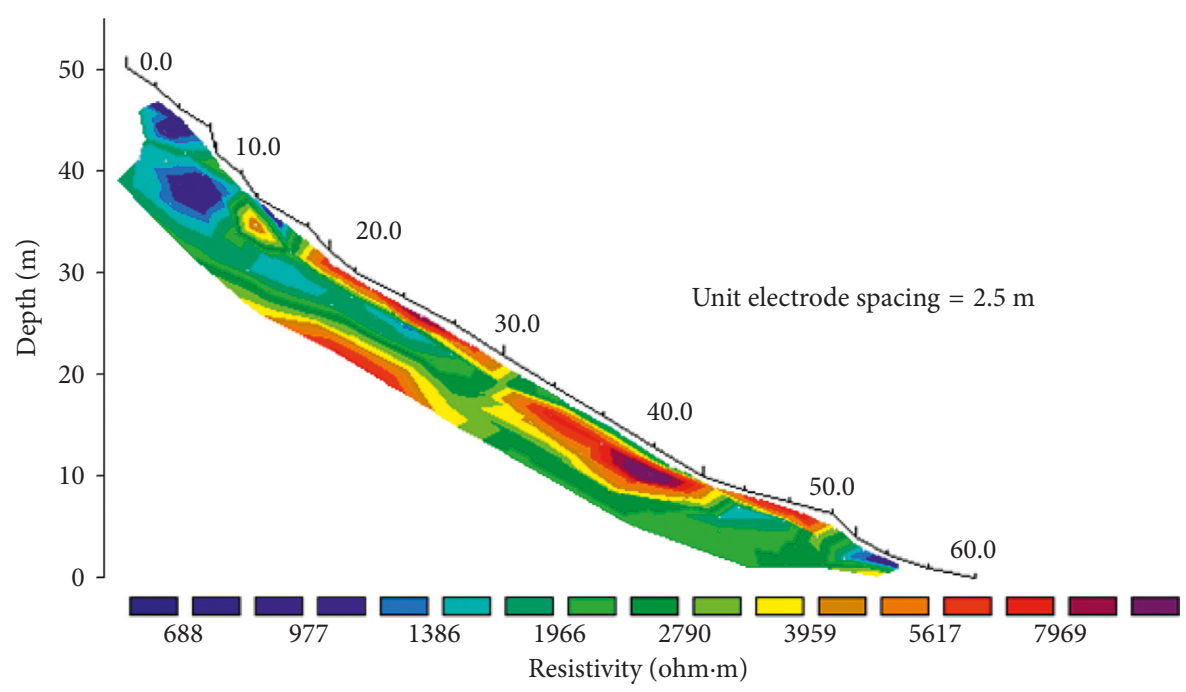

FIGURE 5: Resistivity tomography of the slope.

$\left.126^{\circ} 56^{\prime} 21^{\prime \prime} \mathrm{E}\right)$. This area is underlain by a Gyeonggi gneiss complex that belongs to the Gyeonggi massif, and the bedrock is intensely weathered. The surface is covered by Pinus koraiensis, commonly known as the Korean pine. As a preliminary investigation, the slope length, depth, and gradient were measured for 5 slopes on the study area, and the slope which seems to be vulnerable to landslides (with steep and long slope) was chosen as the study slope. A topographic survey was carried out to clarify the geometrical characteristics of the slope using electronic distance measurement (EDM), slope length and angle approximately being $50 \mathrm{~m}$ and $31^{\circ}$, respectively. Figure 4 shows the location and topographic surface of the study slope.
Electrical resistivity survey was carried out in order to identify soil strata from the resistivity distribution and to select the site investigation point. Resistar RS-100M equipment with multielectrode system ME-100 (Geofyzika A.s.) was used for a multielectrode survey using a Wenner-Schlumberger electrode array with electrode spacing of $2.5 \mathrm{~m}$. Primary data were processed into resistivity cross sections by a 2-D inverse method using the software Res2DInv [48]. Figure 5 shows the resistivity tomography of the slope of the study area.

As shown in Figure 5, the direction of the soil strata can be regarded as parallel to the slope surface, and horizontal autocorrelation is higher than vertical autocorrelation for soil resistivity. Therefore, it is reasonable to generate 


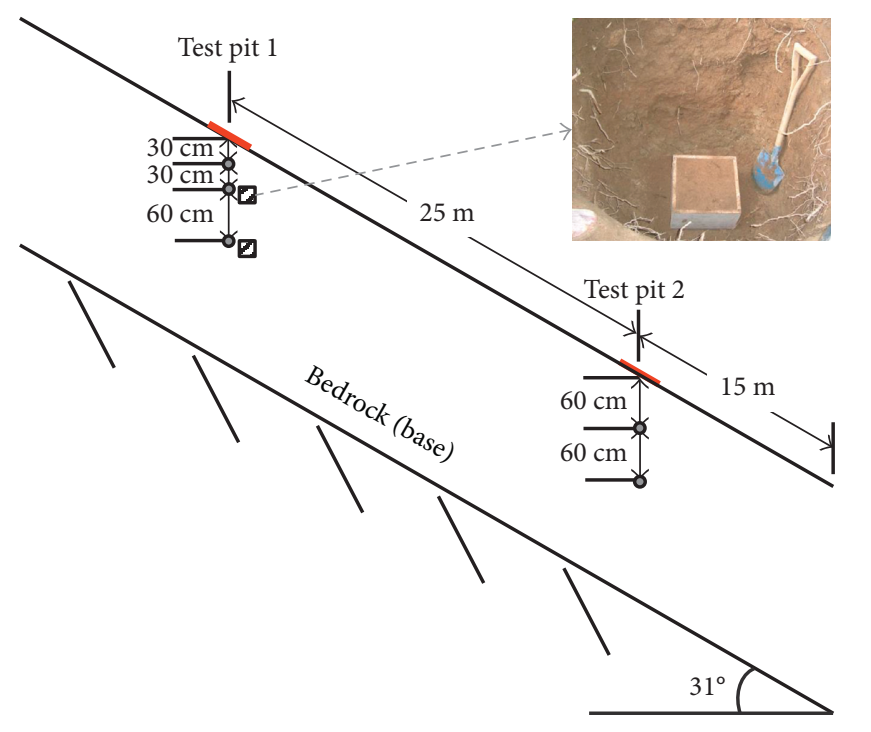

$\begin{array}{ll}\text { - } & \text { Test pit } \\ \text { - } & \text { Disturbed sample } \\ \text { - Block sample (undisturbed) }\end{array}$

FIGURE 6: Location of sampling points.

a random field for the vertical direction on the slope surface. Blue (red) indicates low (high) electrical resistivity. The area with the highest electrical resistivity was in good agreement with the location of the exposed outcrop. The upper slope shows a relatively low resistance value, and it can be assumed that the water content is high [49] and the strength is relatively weak. Therefore, the cross section of the upper slope was selected as the analysis section. Hand auger borings were carried out primarily to identify soil depth and stratum, and two test pits with a size of $1 \mathrm{~m} \times 1 \mathrm{~m}$ were dug. The test pits and soil sampling locations are depicted in Figure 6. The wet unit weight of each sampling depth was obtained by the sand replacement method, and three and two disturbed soil samples were obtained from the upper and lower slope test pits, respectively. The triaxial compression test and the constant head permeability test were carried out to determine the soil physical properties. In addition, the undisturbed samples were also obtained from the upper slope using block sampling and used for the SWCC test. The basic physical properties of soil and slope conditions are summarized in Table 1.

In accordance with the United Soil Classification System (USCS), the soil is classified as SM or SC, and the specific gravity $\left(G_{s}\right)$ of soil is 2.62 . The shear strength test was carried out on soil with a depth of 30,60 , and $120 \mathrm{~cm}$, and the average values for cohesion and friction angle were $14.7 \mathrm{kPa}$ and $17.9^{\circ}$, respectively. The permeability test was also performed on the same depths, and the average saturated permeability $\left(k_{\mathrm{s}}\right)$ was $1.64 \times 10^{-6} \mathrm{~m} / \mathrm{s}$. The random variables selected for the stability analysis are two shear strength parameters $\left(c^{\prime}\right.$ and $\left.\phi^{\prime}\right)$ and saturated permeability. However, the measured data were small, and there was a limit to identifying the statistical characteristics of soil properties by using measured data. Therefore, only the average values of the measured data for $c, \phi$, and $k_{\mathrm{s}}$ were used, and their COV and PDF were assumed through the literatures $[15,30]$. The
TABLE 1: Summary of basic soil properties and slope conditions.

\begin{tabular}{ccc}
\hline & Parameter & Value \\
\hline & Specific gravity, $G_{\mathrm{s}}$ & 2.62 \\
& Water content $(\%)$ & 19.1 \\
Soil property & Dry unit weight, $\gamma_{\mathrm{d}}\left(\mathrm{kN} / \mathrm{m}^{3}\right)$ & 14.7 \\
& Porosity $(\%)$ & 43.1 \\
& Plastic limit $(\%)$ & 15.7 \\
USCS & $\mathrm{SM}, \mathrm{SC}$ \\
\hline \multirow{3}{*}{ Slope } & Length $(\mathrm{m})$ & 50 \\
& Angle $\left({ }^{\circ}\right)$ & 31 \\
& Depth $(\mathrm{m})$ & 2.8 \\
\hline
\end{tabular}

soil properties vary based on the depositional and stress history of the deposit, and its distribution characteristics can be quantitatively reflected through the probability density function (PDF). The PDF type was assumed to be a lognormal distribution for all three parameters, and the coefficient of variation (COV) of $c^{\prime}, \phi^{\prime}$, and $k_{\mathrm{s}}$, was assumed equal to $30 \%, 20 \%$, and $50 \%$, respectively. Phoon and Kulhawy [30] summarized the SOFs and COVs of inherent spatial variability of various soil properties; however, information of soil strength SOF is insufficient. Therefore, the normalized SOFs $(\delta / D)$ were assumed to be $0.1,0.2,0.4,0.8$, 1.5 , and 3.0 for vertical depth to slope surface $(D)$ in order to observe the effect of spatial variability. The statistical properties of the three parameters are summarized in Table 2.

Rainfall infiltration into the soil begins from unsaturated conditions, and it is necessary to identify the permeability characteristics under unsaturated conditions. Therefore, a laboratory test for SWCC was conducted, and parameters of the van Genuchten [47] model were estimated as $\alpha=0.0291, m=0.3473$, and $n=1.532$. The conditions of infiltration analysis are summarized in Table 3 , and SWCC is shown in Figure 7.

4.2. Probabilistic Rainfall Intensity. Rainfall information on the study area is very important because rainfall has a high spatial and temporal variability, and its probabilistic characteristics are very different depending on the region. The information of probability rainfall intensity at the study area was obtained from the Korea precipitation frequency data server of the Ministry of Land, Infrastructure and Transport (MOLIT, http://www.k-idf.re.kr). Figure 8 shows intensityduration-frequency (IDF) curves.

Rainfall intensity for the IDF curve increased as the return period increased, and the smaller the duration, the greater the difference in rainfall intensity. In this study, the probabilistic rainfall intensity for a return period $\left(T_{\mathrm{r}}\right)$ of 2,5 , $10,50,100$, and 200 years was considered. Rainfall events with durations of $1,2,3,6,9,12,15,18$, and 24 hours were chosen for slope analysis, and rainfall intensity is summarized in Table 4.

\section{Results and Discussion}

5.1. Wetting Front Depth and the Factor of Safety. Figure 9 shows the change of wetting front depth (WFD) and the factor of safety depending on rainfall duration. Soil 
TABLE 2: Statistical properties of shear strength parameters.

\begin{tabular}{lccccc}
\hline Soil property & Mean & Standard deviation & COV $(\%)$ & PDF & Scale of fluctuation \\
\hline Cohesion, $c(\mathrm{kPa})$ & 14.7 & 4.41 & 30 & Log-normal & $0.1 D, 0.2 D$ \\
Friction angle, $\phi\left({ }^{\circ}\right)$ & 17.9 & 3.58 & 20 & Log-normal & $0.4 D, 0.8 D$ \\
Permeability, $k_{\mathrm{s}}(\mathrm{m} / \mathrm{s})$ & $1.64 \times 10^{-6}$ & $8.19 \times 10^{-7}$ & 50 & Log-normal & $1.5 D, 3.0 D$ \\
\hline
\end{tabular}

TABLE 3: Conditions of infiltration analysis.

\begin{tabular}{|c|c|c|c|c|c|}
\hline \multirow{3}{*}{$\theta_{0}(\%)$} & \multicolumn{5}{|c|}{ Fitting parameters of van } \\
\hline & $\theta_{\mathrm{s}}(\%)$ & Gen & ten's S & & $\Psi_{\mathrm{mf}}(\mathrm{m})$ \\
\hline & & $\alpha\left(\mathrm{kPa}^{-1}\right)$ & $m$ & $m$ & \\
\hline 28.1 & 41.2 & 0.0286 & 0.3580 & 1.5576 & 0.89 \\
\hline
\end{tabular}

$\theta_{0}$ : initial volumetric water content; $\theta_{s}$ : saturated volumetric water content.

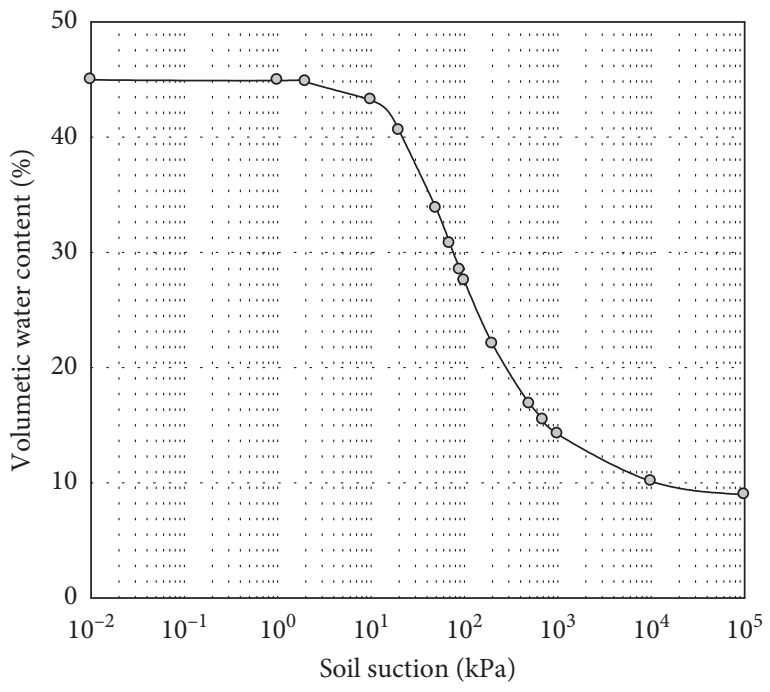

Figure 7: Soil-water characteristic curve.

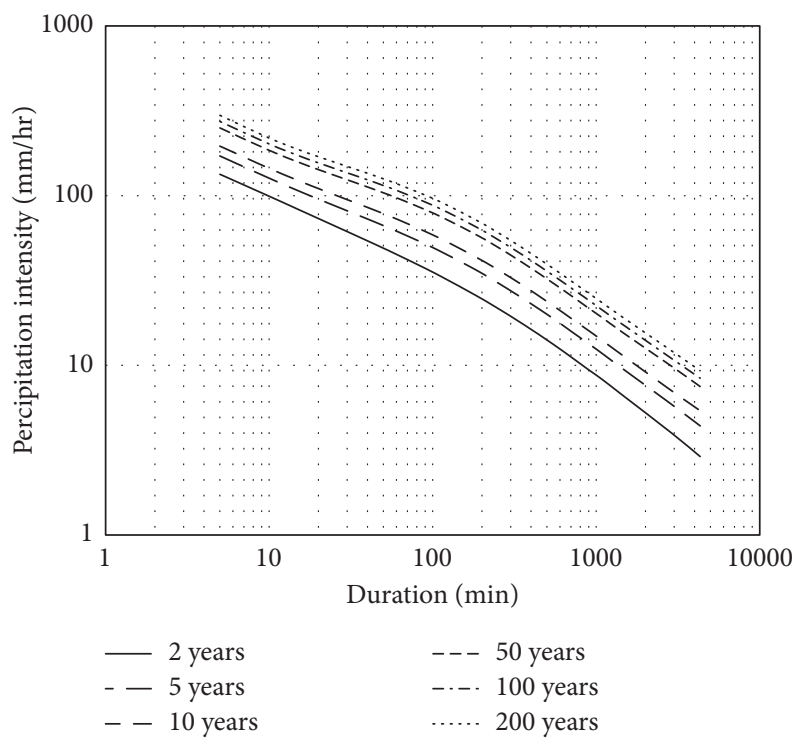

Figure 8: IDF curves for study site.

saturation occurs from the surface due to rainfall infiltration, and the WFD increased with the increase of rainfall duration. The deterministic approach using Chu and Marino [44]
TABLe 4: Probabilistic rainfall intensity $(\mathrm{mm} / \mathrm{h})$ of the study area.

\begin{tabular}{lccccccccc}
\hline $\begin{array}{l}\text { Return } \\
\text { period } \\
\text { (year) }\end{array}$ & 1 & 2 & 3 & 6 & 9 & 12 & 15 & 18 & 24 \\
\hline 2 & 45.1 & 32.3 & 26.1 & 17.4 & 13.4 & 11.0 & 9.4 & 8.3 & 6.7 \\
5 & 61.8 & 45.3 & 36.9 & 24.6 & 19.0 & 15.6 & 13.4 & 11.8 & 9.6 \\
10 & 72.9 & 53.9 & 43.9 & 29.4 & 22.6 & 18.6 & 16.0 & 14.1 & 11.5 \\
50 & 97.2 & 72.8 & 59.6 & 39.9 & 30.7 & 25.3 & 21.7 & 19.2 & 15.7 \\
100 & 107.5 & 80.8 & 66.2 & 44.3 & 34.1 & 28.1 & 24.2 & 21.3 & 17.5 \\
200 & 117.7 & 88.8 & 72.7 & 48.7 & 37.5 & 30.9 & 26.6 & 23.5 & 19.3 \\
\hline
\end{tabular}

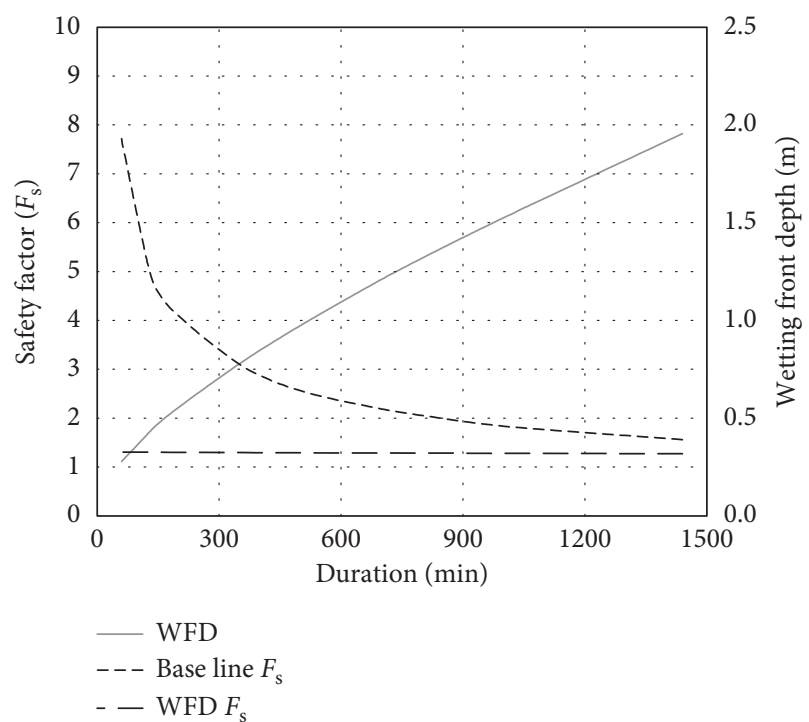

Figure 9: Change in wetting front depth and factor of safety depending on rainfall duration using a deterministic approach.

model was carried out to estimate the WFD and the factor of safety at the baseline and WFD according to the rainfall duration.

The gray line indicates the WDF changes and the dotted lines the changes of FS at the baseline and at the WFD. WFD increases approximately $2 \mathrm{~m}$ when rainfall duration is equal to $24 \mathrm{~h}$, and the factor of safety at WFD was drastically reduced due to the dissipation of negative pore water pressure in unsaturated soil as the rainfall began to penetrate into the ground. The factor of safety at the baseline showed a very small reduction rate considering only an increase in unit weight due to the rainfall infiltration. In the deterministic approach, the factor of safety until a rainfall of $24 \mathrm{~h}$ was greater than 1 . The change in the WFD with the rainfall duration and normalized SOF is shown in Figure 10.

The average WFD showed a significant increase with increasing rainfall duration, but it increased very slightly with normalized SOF. When the return period was low, the 


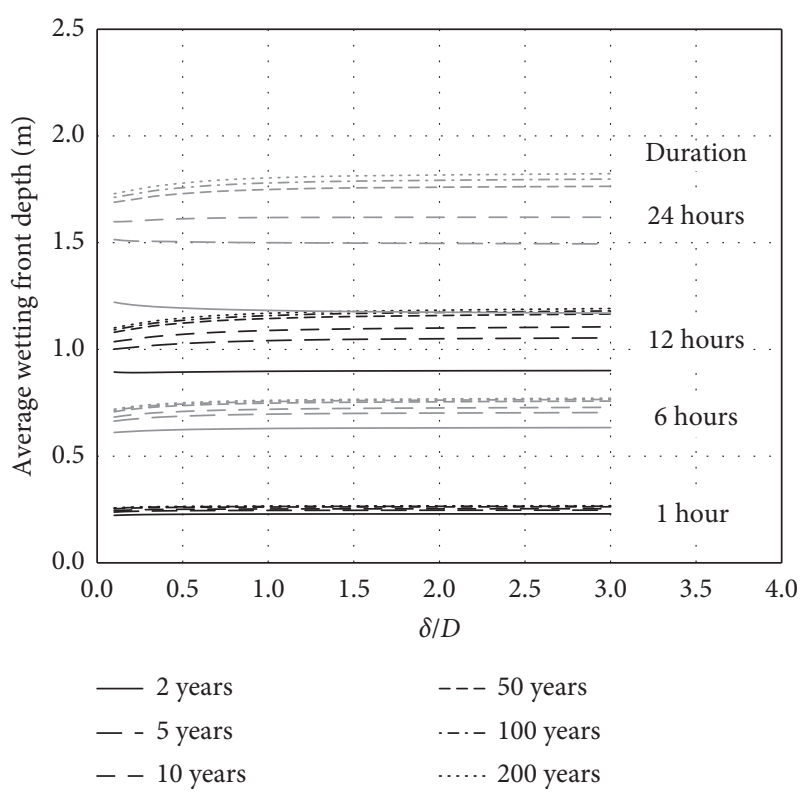

FIGURE 10: Change in wetting front depth depending on rainfall duration and normalized SOF.

difference in average WFD according to the return period was not significant even though there was a large difference in rainfall intensity, whereas the average WFD significantly changed with the return period for high rainfall durations. Although there was no significant difference in average WFD with normalized SOF, there was a large variation in standard deviation. The WFD appeared at various depths depending on the spatial variability of the permeability, and the distribution exhibited a wider range as the rainfall duration increased (Figure 11).

\subsection{Effect of Spatial Variability and Probabilistic Rainfall} Intensity. In this study, the potential failure surface was defined as the deepest depth with a factor of safety of less than 1 , and if the factor of safety is less than 1 at any depth, the slope failure was considered to have occurred. The probability of failure is significantly affected by the return period and the rainfall duration as shown in Figure 12. The effect of the return period increases with rainfall duration because WFD shows a large difference as the rainfall duration increased. However, the effect of the return period decreased as the return period increased, and there was no significant difference in the probability of failure when the return period was over 100 years. This is because the surface runoff occurs when the rainfall intensity exceeds a certain level, and the infiltration is dominated by the infiltration capability of the soil after reaching the initial ponding condition. The spatial variability of soil properties was found to have a major influence. If spatial variability of soil is not considered, the normalized SOF is considered infinity $(\delta / D=\infty)$, and its results showed the lowest probability of failure. This is because the soil is considered to be homogeneous, and it does not take into account the potential failure surface at various depths as the failure surface is fixed to the WFD or the baseline. The impact of the return period

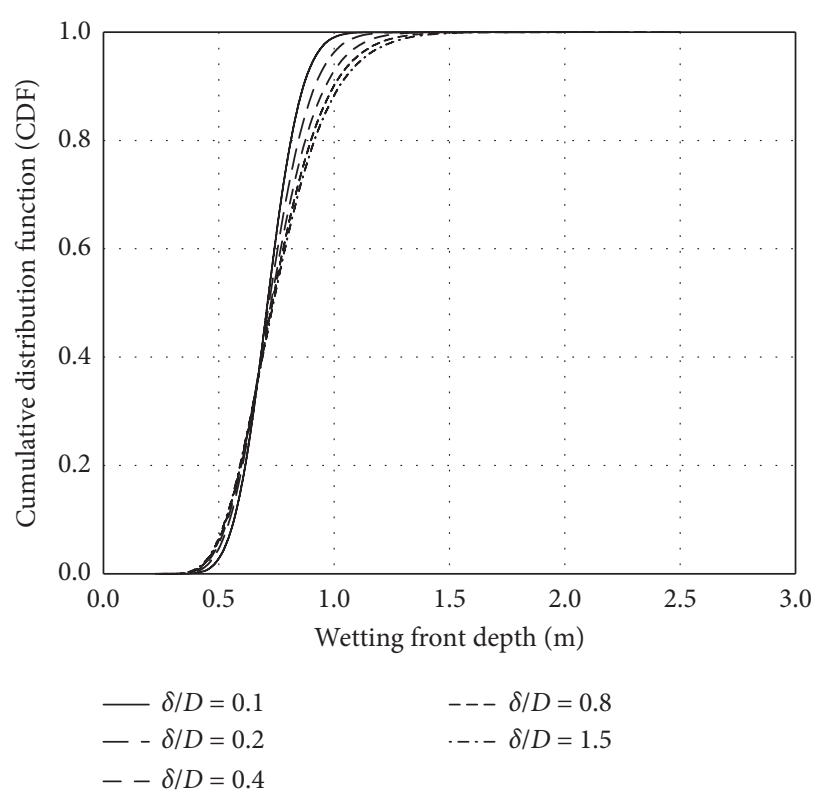

(a)

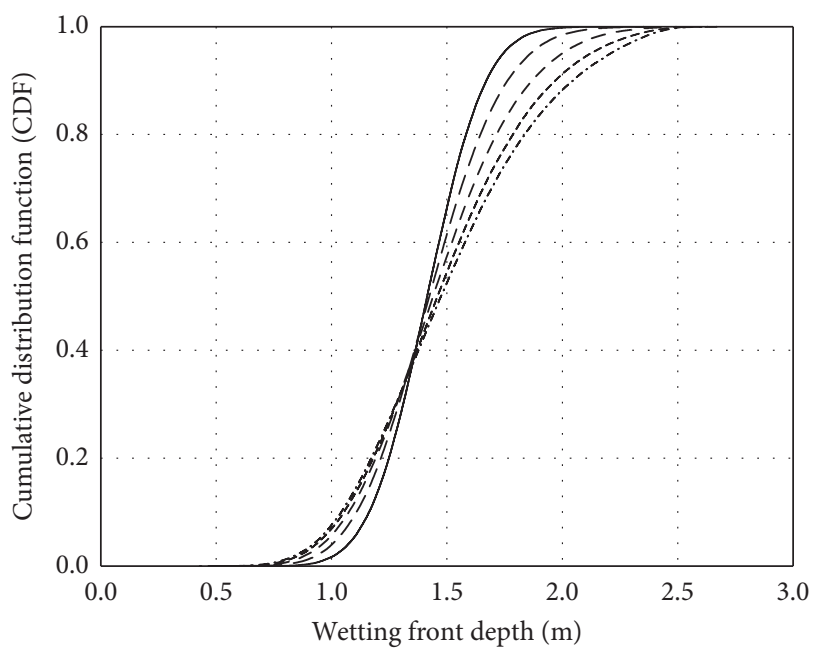

$$
\begin{aligned}
-\delta / D=0.1 & ---\delta / D=0.8 \\
--\delta / D=0.2 & ---\delta / D=1.5 \\
--\delta / D=0.4 &
\end{aligned}
$$

(b)

FIgURE 11: Distribution of WFD according to normalized SOF for rainfall duration of (a) 6 hours and (b) 18 hours.

and the rainfall duration on the probability of failure also varied depending on the spatial variability of soil properties, and the variation of the failure probability with the return period and the rainfall duration was larger as the normalized SOF decreased.

The variation of the probability of failure according to normalized SOF for the return period of 2 and 100 years is shown in Figure 13. The probability of failure decreased with increasing normalized SOF, and it rapidly decreased when the normalized SOF was less than approximately 1 . As identified in various studies $[14,20,22]$, the location of the potential failure surface appeared at various depths in 


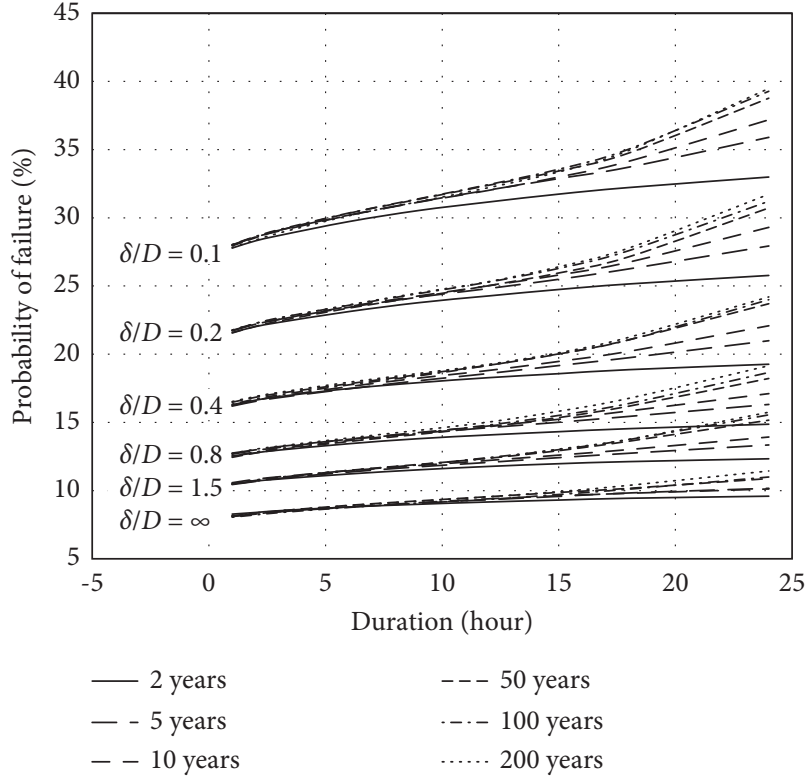

FIGURE 12: Change in the probability of failure depending on the return period and the rainfall duration.

consideration of the spatial variability of soil properties, and the larger the normalized SOF, the lower the probability of failure because the failure occurs at a narrower range of depths. The difference in the probability of failure according to the rainfall duration for the return period of 2 years is smaller than that of the return period of 100 years. The reason is that although the probability of failure is almost the same regardless of the return period for low rainfall duration under the same normalized SOF, the probability of failure increased with the increase of rainfall duration, and its growth rate was larger as the return period is higher as shown in Figure 12.

Figure 14 shows an example of histograms for the frequency of the critical depth where the minimum factor of safety less than 1 occurs and the cumulative failure probability along the depth for 100-year return period and the rainfall duration of 18 hours. The left cumulative distribution and gray histogram are the results for the normalized SOF of 0.1 , and the right cumulative distribution and black histogram are the results for the normalized SOF of 1.5. When the normalized SOF was 0.1, the failure frequency near the baseline was about $19 \%$, whereas that of the normalized SOF of 1.5 was about $40 \%$. The normalized SOF of 0.1 shows higher failure frequency at various depths than that of the normalized SOF of 1.5 , and this is due to the effects of the shear strength parameter as found in the results of Griffiths et al. [14] and the distribution of WFD as shown in Figure 11.

The probability of failure according to the normalized SOF and the rainfall duration for 2 and 100 years return periods were compared with the case where the spatial variability of soil properties was not considered (i.e., homogeneous soil) for each return period, and the differences in probability of failure $\left(\Delta p_{\mathrm{f}}\right)$ are shown in Figure 15. The difference of the failure probability is significantly influenced by the normalized SOF,
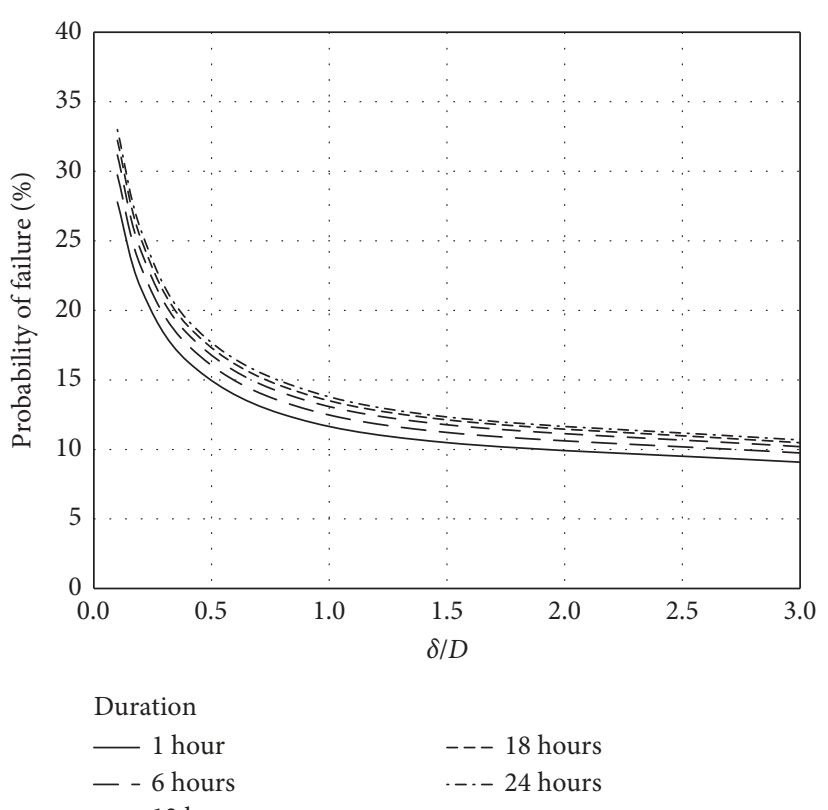

(a)
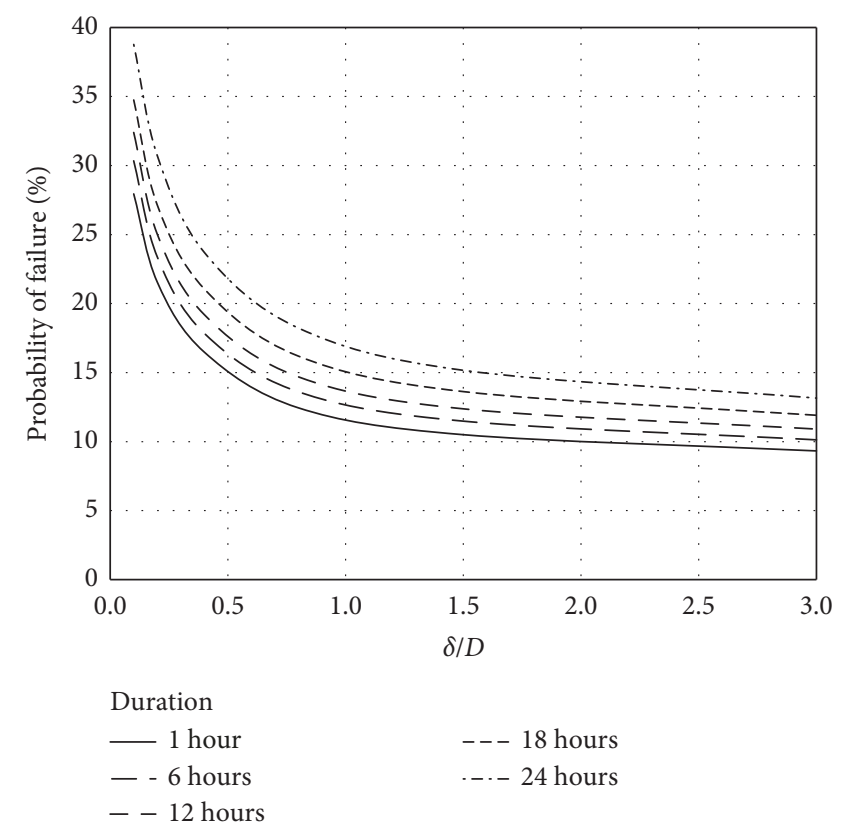

(b)

FIGURE 13: Change in the probability of failure depending on normalized SOF for (a) $T_{\mathrm{r}}=2$ years and (b) $T_{\mathrm{r}}=100$ years.

and the return period and the rainfall duration also have an effect on the difference in probability of failure when the normalized SOF is small. If the normalized SOF is small (i.e., $\delta / D=0.1$ ), a probabilistic difference of approximately $24 \sim 30 \%$ can occur, while the spatial variability of soil properties has little effect on the normalized SOF of three or more. This difference in the probability of failure is influenced by the slope and rainfall conditions and the statistical characteristics of soil properties, and therefore it can be different depending on the target slope. However, it was shown that the 


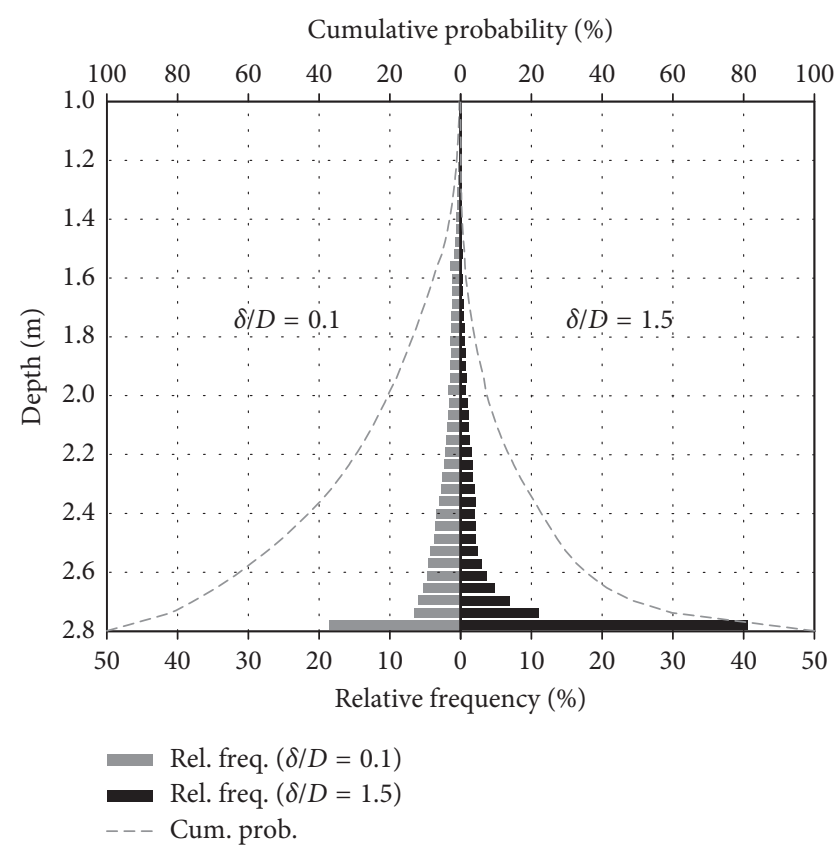

FIgURE 14: Histograms for the frequency of the critical depth and the cumulative failure probability along with the depth $\left(T_{\mathrm{r}}=100\right.$ years and 18 hours rainfall duration).

probabilistic results of the slope stability exhibit noticeable differences that vary with the spatial variability of soil properties, and it is a well-known fact that soil is heterogeneous. Therefore, there is a strong need to consider the spatial variability of soil in practice. In addition, rainfall is a major cause of landslides in South Korea, and the probability of failure of slopes is very different depending on the rainfall condition. Therefore, it is also important to consider the probability rainfall intensity reflecting local rainfall characteristics.

\section{Conclusions}

The purpose of this study was to identify the failure of rainfall-induced landslides considering the spatial variability of soil properties and the probabilistic rainfall intensity through a case study of a weathered soil slope in Korea. An electrical resistivity survey was performed to understand the stratum of the slope. Although the electrical resistivity survey has some inherent limitations as it cannot provide direct information such as shear strength, the distribution of soil strata can be confirmed with images, and information can be provided on soil survey location and direction of random field generation. Herein, three soil properties (i.e., cohesion, friction angle, and permeability) were considered as random fields, and the IDF curves with a 2-, 5-, 10- 50-, 100-, and 200-year return period were applied to identify the effects of probabilistic rainfall intensity. An infinite slope equation for unsaturated soil and multilayer infiltration model by Chu and Marino [44] was used to analyze the slope stability affected by rainfall, and a series of LHS-based Monte Carlo simulations was conducted for probabilistic analysis.

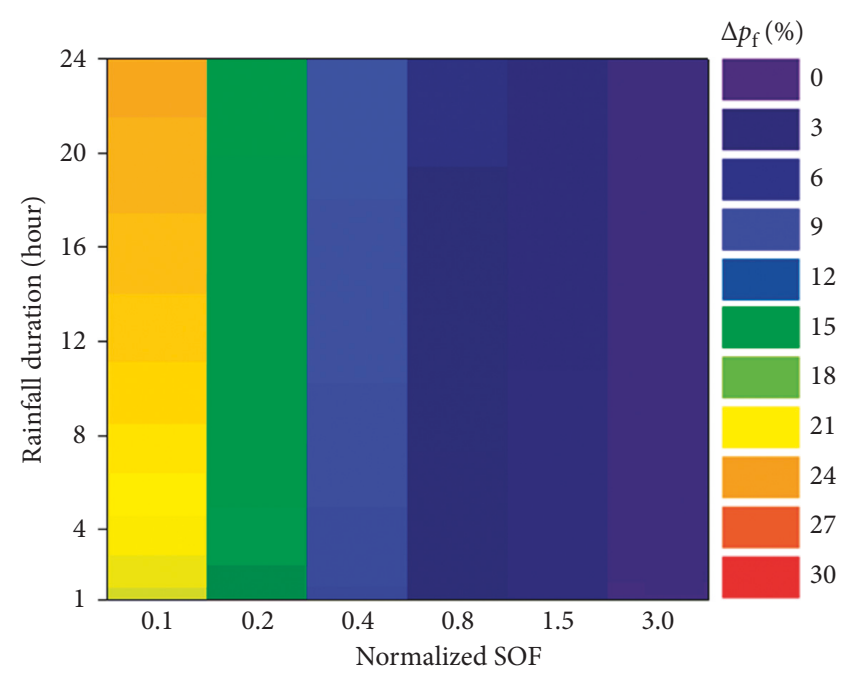

(a)

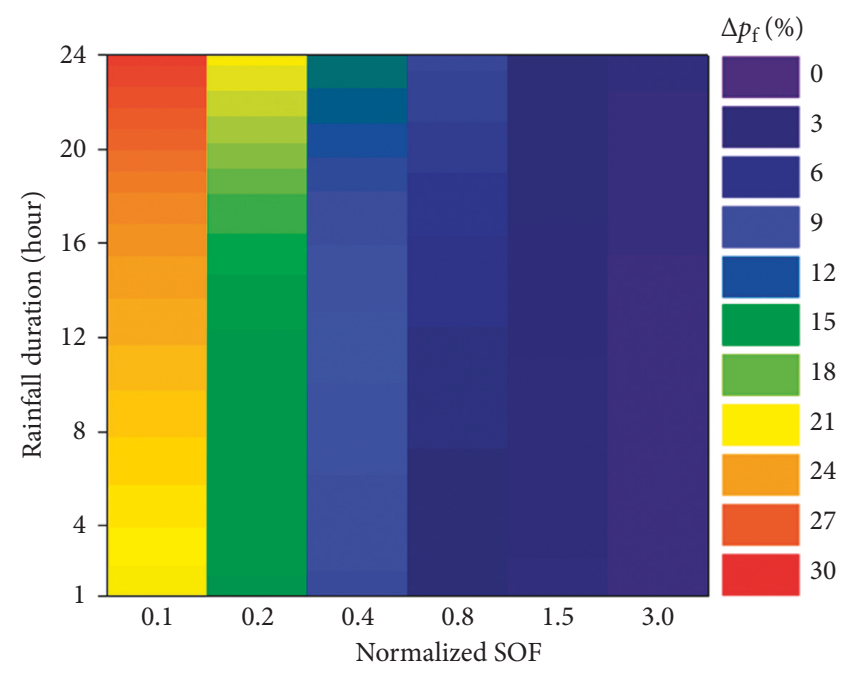

(b)

FIGURE 15: Difference in probability of failure with the results for homogeneous soil $(\delta / D=\infty)$ for (a) $T_{\mathrm{r}}=2$ years and (b) $T_{\mathrm{r}}=100$ years.

Probability of failure was significantly affected by the spatial variability of soil properties, and the results are similar to those of previous studies. The return period and rainfall duration also have a significant impact on slope stability due to the wetting front development. Although the rainfall conditions are the same, their effects on the slope stability were different according to the spatial variability of soil properties, and their effects were more sensitive with decreasing normalized SOF. The probability of failure increased as the return period and the rainfall duration increased. However, the increase rate of the probability of failure decreased as the return period increased, and there was no significant difference in probability of failure when the return period is over 100 years because rainfall infiltration is dominated by the infiltration capability of the soil.

Compared with the results of traditional probabilistic analysis without consideration of the spatial variability of soil properties, the difference in probability of failure was 
found to be approximately $24 \sim 30 \%$ when the normalized SOF was small (i.e., $\delta / D=0.1$ ), and there was little effect of the spatial variability of soil properties for the normalized SOF more than 3. Naturally, the soil is inhomogeneous, and vertical spatial variability of soil properties is typically large. In addition, the probability of failure according to the probability rainfall intensity is greatly influenced by spatial variability of soil properties. Therefore, probabilistic analysis with consideration of spatial variability of soil properties is very important to obtain reasonable results. Although this study applied various SOFs and identified their effects, it is necessary to apply appropriate SOFs to the site in order to accurately estimate the probability of failure. It is well known that the spatial variability in the vertical direction is larger than that in the horizontal direction. This fact was confirmed herein indirectly through an electrical resistivity survey, and it was also confirmed that it is reasonable to generate a random field for the vertical direction on the slope surface. Additionally, this study used the IDF curve generated based on past rainfall data, but the impact of climate change was not reflected. Recently, however, a modified IDF curve has been proposed considering the climate change, and the impacts of climate change can be reflected by the modified IDF curve.

\section{Data Availability}

The data used to support the findings of this study are included within the article.

\section{Conflicts of Interest}

The authors declare that they have no conflicts of interest.

\section{Acknowledgments}

The work of this research had been conducted in the Department of Rural System Engineering, Seoul National University, and the authors would like to thank them for their technical and laboratory support.

\section{References}

[1] A. B. Fourie, D. Rowe, and G. E. Blight, "The effect of infiltration on the stability of the slopes of a dry ash dump," Geotechnique, vol. 49, no. 1, pp. 1-13, 1999.

[2] A. S. Muntohar and H. J. Liao, "Rainfall infiltration: infinite slope model for landslides triggering by rainstorm," Natural Hazards, vol. 54, no. 3, pp. 967-984, 2010.

[3] A. M. Strauch, R. A. Mackenzie, C. P. Giardina, and G. L. Bruland, "Climate driven changes to rainfall and streamflow patterns in a model tropical island hydrological system," Journal of Hydrology, vol. 523, pp. 160-169, 2017.

[4] J. D. Robinson, F. Vahedifard, and A. AghaKouchak, "Rainfall-triggered slope instabilities under a changing climate: comparative study using historical and projected precipitation extremes," Canadian Geotechnical Journal, vol. 54, no. 1, pp. 117-127, 2017.

[5] C. W. W. Ng and Q. Shi, "A numerical investigation of the stability of unsaturated soil slopes subjected to transient seepage," Computers and Geotechnics, vol. 22, no. 1, pp. 1-28, 1998.

[6] J. Kim, S. Jeong, S. Park, and J. Sharma, "Influence of rainfallinduced wetting on the stability of slopes in weathered soils," Engineering Geology, vol. 75, no. 3-4, pp. 251-262, 2004.

[7] P. Frattini, G. Crosta, and R. Sosio, "Approaches for defining thresholds and return periods for rainfall-triggered shallow landslides," Hydrological Processes, vol. 23, no. 10, pp. 14441460, 2009.

[8] H. An, T. T. Viet, G. Lee et al., "Development of time-variant landslide-prediction software considering three-dimensional subsurface unsaturated flow," Environmental Modelling and Software, vol. 85, pp. 172-183, 2006.

[9] S. G. Evans and J. J. Clague, "Recent climatic change and catastrophic geomorphic processes in mountain environments," Geomorphology, vol. 10, no. 1-4, pp. 107-128, 1994.

[10] V. Jomelli, D. Brunstein, D. Grancher, and P. Pech, "Is the response of hill slope debris flows to recent climate change univocal? A case study in the Massif des Ecrins (French Alps)," Climatic Change, vol. 85, no. 1-2, pp. 119-137, 2007.

[11] L. Laloui, A. Ferrari, and J. Eichenberger, "Effect of climate change on landslide behaviour," Geo-Strata, pp. 36-41, October 2010.

[12] M. Floris, A. D'Alpaos, C. Squarzoni, R. Genevois, and M. Marani, "Recent changes in rainfall characteristics and their influence on thresholds for debris flow triggering in the Dolomitic area of Cortina d'Ampezzo, north-eastern Italian Alps," Natural Hazards and Earth System Sciences, vol. 10, no. 3, pp. 571-580, 2010.

[13] L. Schilirò, L. Montrasio, and G. S. Mugnozza, "Prediction of shallow landslide occurrence: validation of a physically-based approach through a real case study," Science of the Total Environment, vol. 569-570, pp. 134-144, 2016.

[14] D. V. Griffiths, J. Huang, and G. A. Fenton, "Probabilistic infinite slope analysis," Computers and Geotechnics, vol. 38, no. 4, pp. 577-584, 2011.

[15] S. Lacasse and F. Nadim, "Uncertainties in characterizing soil properties," in Uncertainty in the Geologic Environment (GSP 58), C. D. Shackelford, P. P. Nelson, and M. J. S. Roth, Eds., pp. 49-75, ASCE, New York, NY, USA, 1996.

[16] R. Webster and M. A. Oliver, Geostatistics for Environmental Scientists, Wiley, Chichester, UK, 2nd edition, 2007.

[17] S. E. Cho, "Effects of spatial variability of soil properties on slope stability," Engineering Geology, vol. 92, no. 3-4, pp. 97-109, 2007.

[18] D. V. Griffiths, J. Huang, and G. A. Fenton, "Influence of spatial variability on slope reliability using 2-D random fields," Journal of Geotechnical and Geoenvironmental Engineering, vol. 135, no. 10, pp. 1367-1378, 2009.

[19] S. H. Jiang, D. Q. Li, L. M. Zhang, and C. B. Zhou, "Slope reliability analysis considering spatially variable shear strength parameters using a non-intrusive stochastic finite element method," Engineering Geology, vol. 168, pp. 120-128, 2014.

[20] S. E. Cho, "Probabilistic stability analysis of rainfall-induced landslides considering spatial variability of permeability," Engineering Geology, vol. 171, pp. 11-20, 2014.

[21] H. Q. Dou, T. C. Han, X. N. Gong, Z. Y. Qiu, and Z. N. Li, "Effects of the spatial variability of permeability on rainfallinduced landslides," Engineering Geology, vol. 192, pp. 92-100, 2015.

[22] D. Q. Li, X. H. Qi, K. K. Phoon, L. M. Zhang, and C. B. Zhou, "Effect of spatially variable shear strength parameters with 
linearly increasing mean trend on reliability of infinite slopes," Structural Safety, vol. 49, pp. 45-55, 2014.

[23] D. Q. Li, S. H. Jiang, Z. J. Cao, W. Zhou, C. B. Zhou, and L. M. Zhang, "A multiple response-surface method for slope reliability analysis considering spatial variability of soil properties," Engineering Geology, vol. 187, pp. 60-72, 2015.

[24] J. S. Cai, T. C. J. Yeh, E. C. Yan, Y. H. Hao, S. Y. Huang, and J. C. Wen, "Uncertainty of rainfall-induced landslides considering spatial variability of parameters," Computers and Geotechnics, vol. 87, pp. 149-162, 2017.

[25] F. Guzzetti, S. Peruccacci, M. Rossi, and C. P. Stark, "The rainfall intensity-duration control of shallow landslides and debris flows: an update," Landslides, vol. 5, no. 1, pp. 3-17, 2008.

[26] M. Kallache, M. Vrac, P. Naveau, and P. A. Michelangeli, "Nonstationary probabilistic downscaling of extreme precipitation," Journal of Geophysical Research, vol. 116, article D05113, 2011.

[27] M. D. McKay, R. J. Beckman, and W. J. Conover, "A comparison of three methods for selecting values of input variables in analysis of output from a computer code," Technometrics, vol. 21, no. 2, pp. 239-245, 1979.

[28] M. A. Hicks and C. Onisiphorou, "Stochastic evaluation of static liquefaction in a predominantly dilative sand fill," Géotechnique, vol. 55, no. 2, pp. 123-133, 2005.

[29] E. H. Vanmarcke, Random Fields: Analysis and Synthesis, MIT Press, Cambridge, MA, USA, 1983.

[30] K. K. Phoon and F. H. Kulhawy, "Characterization of geotechnical variability," Canadian Geotechnical Journal, vol. 36, no. 4, pp. 612-624, 1999.

[31] D. J. DeGroot and G. B. Baecher, "Estimating autoconvariance of in-situ soil properties," Journal of Geotechnical and Geoenvironmental Engineering, vol. 119, no. 1, pp. 147-166, 1993.

[32] G. A. Fenton, "Estimation for stochastic soil models," Journal of Geotechnical and Geoenvironmental Engineering, vol. 125, no. 6, pp. 470-485, 1999.

[33] G. B. Baecher and J. T. Christian, Reliability and Statistics in Geotechnical Engineering, John Wiley \& Sons, Hoboken, NJ, USA, 2003.

[34] M. Uzielli, G. Vannucchi, and K. K. Phoon, "Random field characterisation of stress-normalised cone penetration testing parameters," Géotechnique, vol. 55, no. 1, pp. 3-20, 2005.

[35] B. Sudret and A. Der Kiureghian, "Stochastic finite element methods and reliability: a state-of-the-art report," Tech. Rep. UCB/SEMM-2000/08, Department of Civil and Environmental Engineering, University of California (UC), Berkeley, CA, USA, 2000.

[36] P. D. Spanos and R. G. Ghanem, "Stochastic finite element expansion for random media," Journal of Engineering $\mathrm{Me}$ chanics, vol. 115, no. 5, pp. 1035-1053, 1989.

[37] D. Zhang and Z. Lu, "An efficient, high-order perturbation approach for flow in random porous media via KarhunenLoeve and polynomial expansions," Journal of Computational Physics, vol. 194, no. 2, pp. 773-794, 2004.

[38] J. Brejda, J. Moorman, T. B. Smith, J. L. Karlen, D. L. Allan, and T. H. Dao, "Distribution and variability of surface soil properties at a regional scale," Soil Science Society of America Journal, vol. 64, no. 3, pp. 974-982, 2000.

[39] G. A. Fenton and D. V. Griffiths, "Bearing capacity prediction of spatially random $c-\phi$ soils," Canadian Geotechnical Journal, vol. 40, no. 1, pp. 54-65, 2003.

[40] S. E. Cho and S. R. Lee, "Instability of unsaturated soil slopes due to infiltration," Computers and Geotechnics, vol. 28, no. 3, pp. 185-208, 2001.
[41] W. H. Green and C. A. Ampt, "Studies on soil physics, part 1, the flow of air and water through soils," Journal of Agricultural Science, vol. 4, pp. 1-24, 1911.

[42] Z. Chen, R. S. Govindaraju, and M. L. Kavvas, "Spatial averaging of unsaturated flow equations under infiltration conditions over areally heterogeneous fields: 1 . Development of models," Water Resources Research, vol. 30, no. 2, pp. 523-533, 1994.

[43] R. S. Govindaraju, C. Corradini, and R. Morbidelli, "A semianalytical model of expected areal-average infiltration under spatial heterogeneity of rainfall and soil saturated hydraulic conductivity," Journal of Hydrology, vol. 316, no. 1-4, pp. 184-194, 2006.

[44] X. Chu and M. A. Marino, "Determination of ponding condition and infiltration into layered soils under unsteady rainfall," Journal of Hydrology, vol. 313, no. 3-4, pp. 195-207, 2005.

[45] D. G. Fredlund and H. Rahardjo, Soil Mechanics for Unsaturated Soils, John Wiley \& Sons, New York, NY, USA, 1993.

[46] D. G. Fredlund, N. R. Morgenstern, and R. A. Widger, "The shear strength of unsaturated soils," Canadian Geotechnical Journal, vol. 15, no. 3, pp. 313-321, 1978.

[47] M. T. van Genuchten, "Closed-form equation for predicting the hydraulic conductivity of unsaturated soils," Soil Science Society of America Journal, vol. 44, no. 5, pp. 892-898, 1980.

[48] M. H. Loke and R. D. Barker, "Least-squares deconvolution of apparent resistivity pseudosections," Geophysics, vol. 60, no. 6, pp. 1682-1690, 1995.

[49] A. Samouëlian, I. Cousin, A. Tabbagh, A. Bruand, and G. Richard, "Electrical resistivity survey in soil science: a review," Soil and Tillage Research, vol. 83, no. 2, pp. 173-193, 2005. 


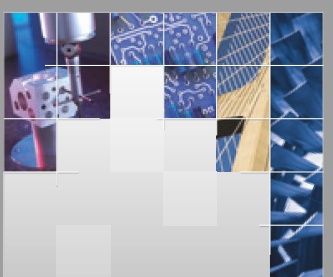

\section{Enfincering}
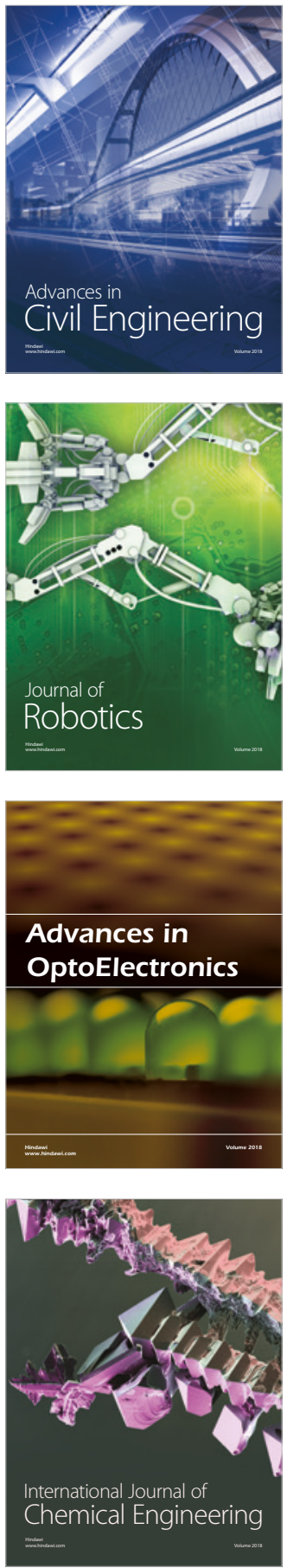

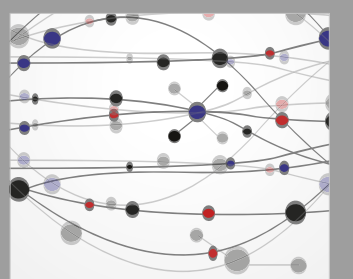

\section{Rotating \\ Machinery}

The Scientific World Journal

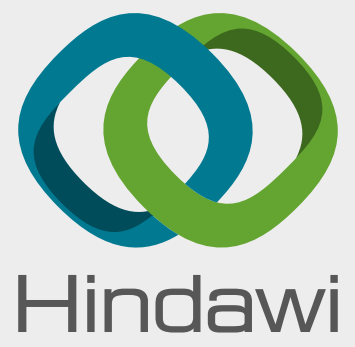

Submit your manuscripts at

www.hindawi.com
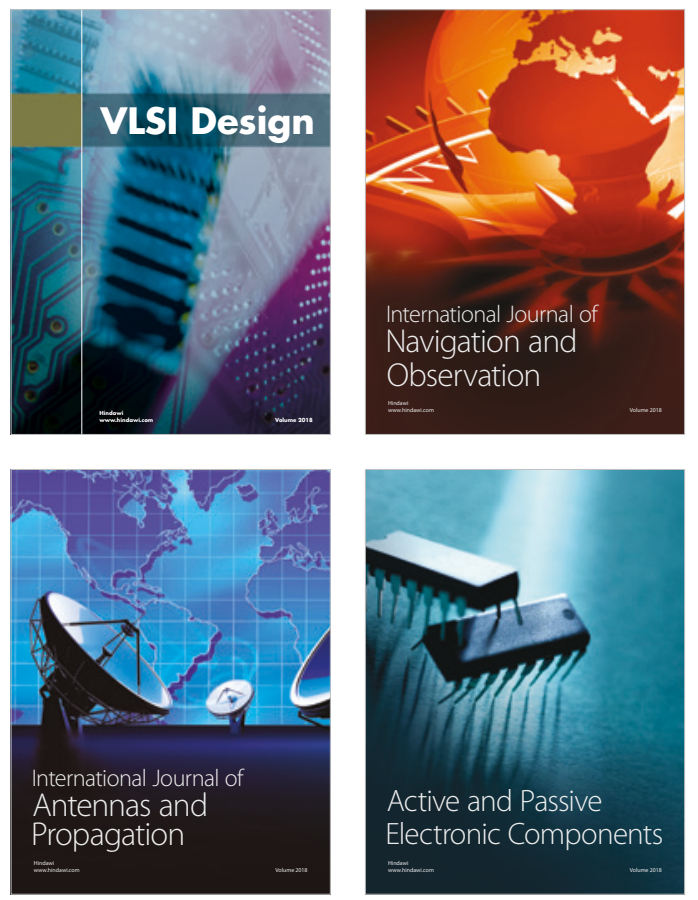
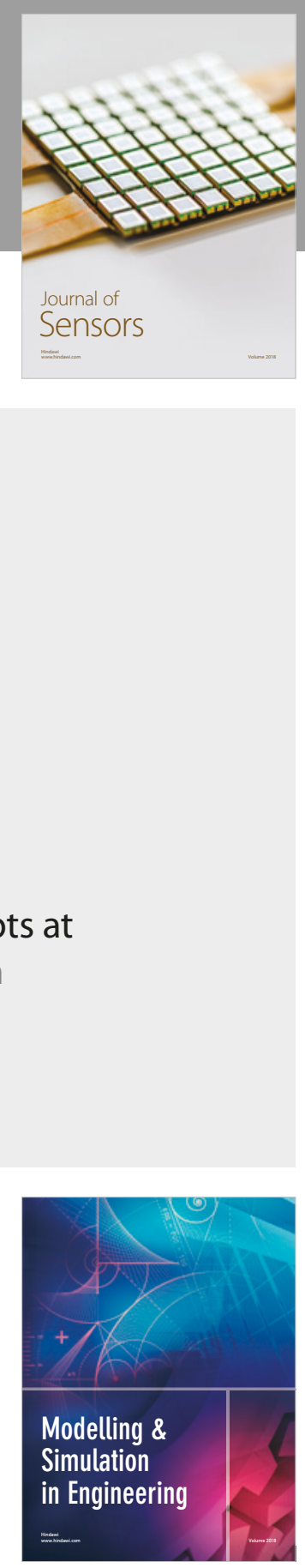

\section{Advances \\ Multimedia}
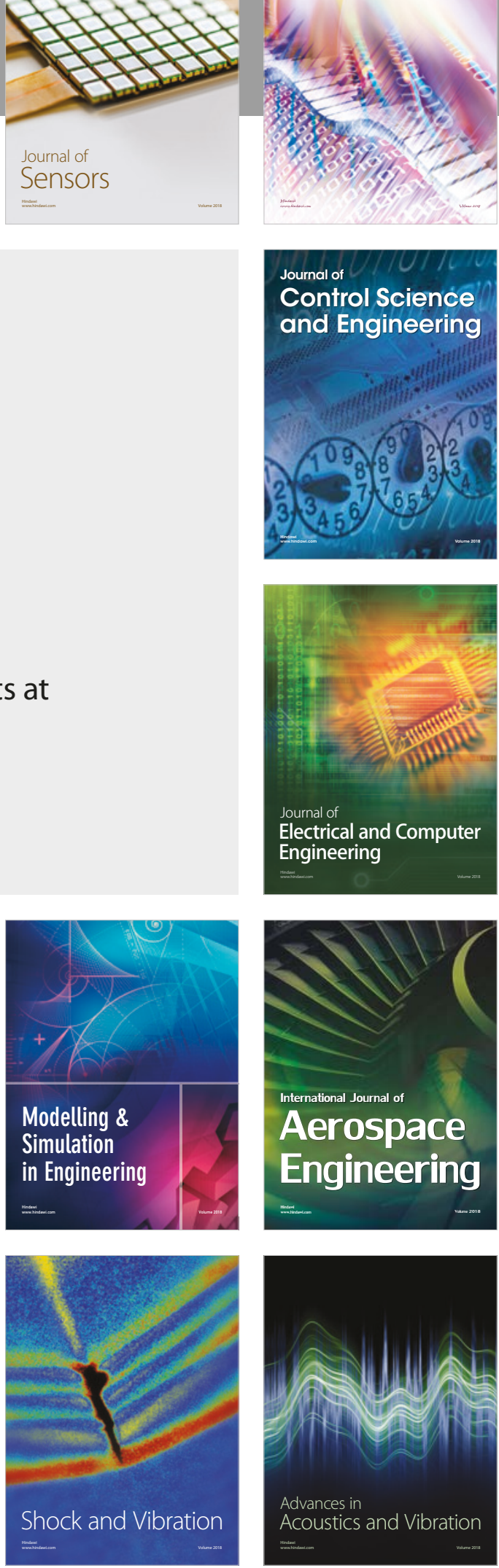